\title{
EXSOLUÇÕES EM CROMO-ESPINÉLIOS
}

\author{
MARIA ANGELA FORNONI CÂNDIA* \& JOSÉ CARLOS GASPAR*
}

\begin{abstract}
EXSOLUTION IN CHROME-SPINEL Chrome-spinel composition is largely used for petrogenetic interpretations. Most mafic/ultramafic rock occurrences underwent metamorphism which may impose modification to the original spinel chemical composition. Internally consistent thermodynamic calculations show large miscibility gaps for $(\mathrm{Fe}, \mathrm{Mg})\left(\mathrm{Al}, \mathrm{Fe}^{3}, \mathrm{Cr}\right)_{2} \mathrm{O}_{4}$ spinels in between $500^{\circ} \mathrm{C}$ and $600^{\circ} \mathrm{C}$. Exsolution in natural chromian spinels agrees well with the calculated model. The two most common exsolved phases are $\mathrm{Mg}\left(\mathrm{Al}, \mathrm{Cr}>\mathrm{O}_{4}\right.$ and $\mathrm{Fe}\left(\mathrm{Fe}, \mathrm{Cr}>{ }_{2} \mathrm{O}_{4}\right.$ which occur as intergrown lamellae, blebs, rods or composite grains. In more evolved systems both phases may form discrete crystals. Ilmenite may be produced by oxidation exsolution in ferrian chrome-spinel crystals or in the $\mathrm{Fe}(\mathrm{Fe}, \mathrm{Cr})_{2} \mathrm{O}_{4}$ exsolved phases. Under metamorphic conditions of clinochlore stability field, the $\mathrm{Mg}(\mathrm{Al}, \mathrm{Cr})_{2} \mathrm{O}_{4}$ component may enter silicate reactions and be entirely consumed. Above the clinochlore stability field $\mathrm{MgAl}_{3} \mathrm{O}_{4}$ may be produced. Whenever petrogenetic interpretations are based on chromian spinel composition from metamorphosed rocks it is necessary to investigate the assemblage evolution. Magmatic interpretations may not be possible.
\end{abstract}

Keywords: chrome-spinel, exsolution. petrogenesis

RESUMO A composicão dos espinélios cromíferos é amplamente utilizada para interpretações petrogenéticas. A maioria das ocorrências de rochas máficas/ultramáficas foi submetida a metamorfismo, o qual pode levar a modificações da composicão química do espinélio original. Cálculos termodinâmicos mostram grandes lacunas de miscibilidade para espinélios de composição geral $(\mathrm{Fe}, \mathrm{Mg})\left(\mathrm{Al}, \mathrm{Fe}^{+3}, \mathrm{Cr}\right)_{2} \mathrm{O}_{4}$ entre $500^{\circ} \mathrm{C}$ e $600^{\circ} \mathrm{C}$. Exsolução em cromo-espinélios naturais concordam bem com o modelo calculado. As duas fases mais comumente exsolvidas são $\mathrm{Mg}(\mathrm{Al}, \mathrm{Cr})_{2} \mathrm{O}_{4}$ e $\mathrm{Fe}(\mathrm{Fe}, \mathrm{Cr})_{2} \mathrm{O}_{4}$, que podem ocorrer como lamelas, porcões, bastonetes e grãos compostos. Em sistemas mais desenvolvidos as duas fases podem formar cristais discretos. Ilmenita pode ser produzida por exsolução por oxidação em cristais de cromo-espinélio ferrífero ou em fases exsolvidas de composição $\mathrm{Fe}(\mathrm{Fe}, \mathrm{Cr})_{2} \mathrm{O}_{4}$. Em condições metamórficas correspondentes ao campo de estabilidade do clinocloro, o componente $\mathrm{Mg}(\mathrm{Al}, \mathrm{Cr}){ }_{2} \mathrm{O}_{4}$ pode entrar em reações de silicatos e ser completamente consumido. Acima do campo de estabilidade do clinocloro $\mathrm{MgAl}_{3} \mathrm{O}_{4}$ pode ser produzido. Sempre que interpretacões petrogenéticas forem baseadas em composicões de cromo-espinélios de rochas metamorfizadas torna-se imprescindível uma investigação detalhada da evolução paragenética das rochas. Interpretações magmáticas podem não ser possíveis.

Palavras-chaves: cromo-espinélios, exsolução, petrogênese

INTRODUÇÃO As variações composicionais dos cromo-espinélios em rochas ultramáficas têm sido amplamente discutidas na literatura geológica, principalmente com relação às suas implicacões petrogenéticas (e.g. Irvine 1967, Dick \& Bullen 1984, Haggerty 1991). Campos composicionais são definidos em função do tipo de ocorrência e do contexto geotectônico (Dick \& Bullen 1984, Stowe 1994). O princípio subjacente a esse tipo de interpretação é que a composição do cromo-espinélio reflete as condições do ambiente em que se formou e que sua composicão não sofreu modificações posteriores. Em território brasileiro, onde as ocorrências de rochas ultramáficas estão geralmente metamorfizadas em diferentes ciclos orogenéticos e graus metamórficos sendo, portanto, fundamental o entendimento das possíveis modificações impostas às composições dos cromo-espinélios pêlos processos subsequentes à sua formação. Tais modificações podem dificultar ou inviabilizar interpretações petrogenéticas e/ou tectônicas baseadas nas composições desses minerais. No presente trabalho são consideradas as exsoluções que ocorrem em cromo-espinélios em condições sub-solidus.

VARIACÕES COMPOSICIONAIS DE CROMOESPINÉLIOS Há uma grande quantidade de informação na literatura sobre os campos composicionais dos cromoespinélios nos vários tipos de ocorrência e ambientes geotectônicos. Na Figura 1 estão mostrados os campos correspondentes a duas formas de ocorrência muito comuns; os complexos estratiformes e as rochas do manto superior (Irvine 1967, Haggerty 1991, 1994). O campo composicional dos cromo-espinélios do manto superior engloba os ofíolitos e xenólitos de plagioclásio lherzolito, espinélio lherzolito, granada lherzolito e harzburgito. Genericamente, os cromoespinélios mantélicos mostram uma extensa variação na razão
$\mathrm{Cr} /(\mathrm{Cr}+\mathrm{Al})$, a qual é o reflexo de diferentes taxas de fusão parcial no manto, enquanto que nos cromo-espinélios de complexos estratiformes esta razão apresenta, relativamente, pequena variação. Nestes últimos espinélios é mais significativa a variação na razão $\mathrm{Mg} /\left(\mathrm{Mg}+\mathrm{Fe}^{+}\right)$resultante da cristalização fracionada dos magmas (Irvine 1967, Dick \& Bullen 1984).

EXSOLUÇÕES Desenvolvimentos termodinâmicos realizados por Sack \& Ghiorso (1991a, b) para espinélios cromíferos mostram a existência de várias lacunas de miscibilidade entre membros cromíferos, aluminosos e ferríferos. A Figura 2 mostra os resultados obtidos por esses autores para os espinélios $(\mathrm{Fe}, \mathrm{Mg})\left(\mathrm{Al}, \mathrm{Fe}^{+3}, \mathrm{Cr}\right){ }_{2} \mathrm{O}_{4}$, no intervalo de temperatura entre 500 e $600^{\circ} \mathrm{C}$, em equilíbrio com olivinas $\mathrm{Fo}_{0}, \mathrm{Fo}_{80}, \mathrm{Fo}_{90}, \mathrm{FO}_{95}$ e $\mathrm{Fo}_{100}$. Ressalta nesses diagramas a existência da lacuna de miscibilidade entre os termos $(\mathrm{Fe}, \mathrm{Mg}) \mathrm{Al}_{2} \mathrm{O}_{4}$ e $(\mathrm{Fe}, \mathrm{Mg}) \mathrm{Fe}_{2} \mathrm{O}_{4}$ em todas as condições investigadas pêlos autores (Figuras 2a a 2e). Entre os termos $(\mathrm{Fe}, \mathrm{Mg}) \mathrm{Cr}_{2} \mathrm{O}_{4}$ e $(\mathrm{Fe}, \mathrm{Mg}) \mathrm{Fe}_{2} \mathrm{O}_{4}$ a lacuna de miscibilidade se instala a temperaturas iguais ou inferiores a $550^{\circ} \mathrm{C}$, com exceção de espinélios em equilíbrio com olivina Foioo (Figura 2a a 2e). Por outro lado, a lacuna entre $(\mathrm{Fe}, \mathrm{Mg}) \mathrm{Cr}_{2} \mathrm{O}_{4} \mathrm{e}$ $(\mathrm{Fe}, \mathrm{Mg}) \mathrm{AhO} 4$ somente aparece em espinélios em equilíbrio com olivinas $\mathrm{Fo}_{90}$ a $\mathrm{Fo}_{95}$, exceto para o caso de temperaturas iguais ou superiores a $600^{\circ} \mathrm{C}$ e em equilíbrio com $\mathrm{Fo}_{95}$ (Figuras 2c e 2d). Destaca-se nos diagramas que, dependendo da composição, a exsolução pode originar associações de duas ou três fases.

Exemplos de ocorrências A ocorrência de exsoluções em espinélios cromíferos é citada por vários autores; a maioria reporta a desmistura entre as fases 


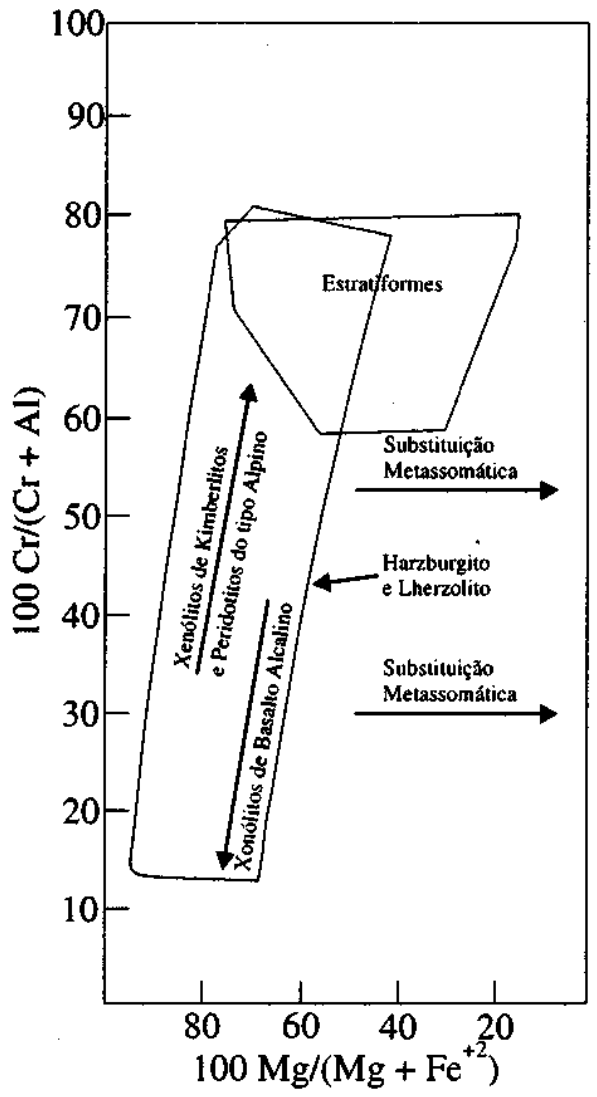

Figura 1 - Campos composicionais de espinélios do manto superior (Haggerty 1991, 1994) e de complexos estratiformes (Irvine 1967). As setas indicam as principais substituições; $\mathrm{Cr} \leftrightarrow \rightarrow A l$ e Fe $e^{+2} \leftrightarrow \rightarrow M g$.

Figure 1 - Compositional range of upper mantle spinels (Haggerty 1991, 1994) and stratiform complexes (Irvine 1967). Arrows indicate the two main substitutions; $\mathrm{Cr} \leftarrow \rightarrow \mathrm{Al}$ and $\mathrm{Fe}^{+2} \leftarrow \rightarrow \mathrm{Mg}$.

(Fe,Mg) $\mathrm{Al}_{2} \mathrm{O}_{4}$ e (Fe,Mg)Fe ${ }_{2} \mathrm{O}_{4}$ (e.g. Purvis et al. 1972, Muir \& Naldrett 1973, Springer 1974, Steele et al. 1977, Nilson 1981, Loferski \& Lipin 1983, Jan et al 1992, Cândia \& Gaspar 1996).

Purvis et al. (1972) descrevem lamelas de composição aluminosa em espinélios cromíferos do Complexo Carr Boyd, na Austrália.

Muir \& Naldrett (1973) relatam a existência de grãos de espinélios compostos por duas fases em rochas ultramáficas de Giant Nickel Mine, BC, Canada. A forma de exsolução varia desde porções irregulares e bem delimitadas, ricas em (Fe,Mg)Fe2O4, hospedadas em fase rica em (Fe,Mg)AhO4, até grãos compostos onde as duas fases formam somente duas porções contínuas.

Springer (1974) cita a existência da associação de espinélios aluminosos e ferríferos, em grãos distintos ou intercrescidos, em rochas ultramáficas submetidas a metamorfismo de contato em Serra Nevada, Califórnia.

Steele et al. (1977) descrevem exsolução em espinélios cromíferos em rochas máficas e ultramáficas metamorfizadas em fácies granulito, pertencentes ao Complexo Fiskenaesset, Groelândia Oeste. As texturas incluem finas lamelas, porções com variadas dimensões, grãos compostos por duas fases e grãos distintos. Tais texturas são interpretadas como resultantes de reequilíbrio metamórfico.

Nilson (1981) estudou espinélios cromíferos do Complexo Máfico-Ultramáfico de Americano do Brasil, GO. São intercrescimentos de duas fases, com porções aluminosas e ferríferas discretas, intercrescidas em formas irregulares. Tais intercrescimentos são interpretados pelo autor como decorrentes do metamorfismo de fácies anfibolito ao qual foi submetido o complexo.

Loferski e Lipin (1983) descrevem detalhadamente as exsoluções em cromitas do distrito de Red Lodge, Montana, USA. As cromitas ocorrem em rochas ultramáficas metamorfizadas em fácies anfibolito alto/granulito. As texturas descritas incluem porções e lamelas de fase aluminosa na fase ferrífera e vice-versa. Os autores associam o desenvolvimento da exsolução ao pico metamórfico de aproximadamente $600^{\circ} \mathrm{C}$.

Jan et al. (1992) descrevem a ocorrência de exsoluções em cromo-espinélios presentes em rochas ultramáficas associadas ao complexo máfico ultramáfico de Chilas, Paquistão. As exsoluções são descritas como porções, lamelas e bastonetes de composição magnetítica exsolvida em fase de composição aluminosa. O desenvolvimento contínuo de finas lamelas sugere que o processo de exsolução deve ter sido prolongado.

Cândia \& Gaspar (1996) descrevem exsoluções em cromo-espinélios de rochas ultramáficas dos complexos máfico-ultramáficos de Mangabal I e II. Os cromo-espinélios ocorrem em rochas metaperidotíticas, inclusos em olivinas.

$\mathrm{Na}$ Figura 3 encontra-se delimitado um campo no qual estão contidas as curvas solvus determinadas pêlos diversos autores, a partir das composições das fases exsolvidas das ocorrências naturais acima mencionadas. Esse campo mostra claramente a existência de solvi entre os componentes $\mathrm{Al}_{2} \mathrm{O}_{5}$ e FezOs concordantes com aqueles calculados por Sack \& Ghiorso (1991 b). A posição exata das várias curvas solvus dentro desse campo é função principalmente da paragênese e da temperatura em que os espinélios sofreram a desmistura; quanto maior a temperatura menor é a lacuna de miscibilidade e as curvas afastam-se do polo do $\mathrm{Cr}$.

Os espinélios de complexos estratiformes e alaskianos possuem campos composicionais que apresentam sobreposição parcial com a lacuna de miscibilidade (Figura 3) e que, se submetidos a condições que possibilitem a ocorrência de exsolução, ela deverá acontecer (ver Discussões). Por outro lado, espinélios de rochas do manto superior e de algumas suites de alto grau metamórfico que possuem composições químicas semelhantes às rochas mantélicas (Evans \& Frost 1975 , não mostradas na figura), possuem campo composicional com sobreposição mínima com a lacuna de miscibilidade, devendo portanto, raramente apresentar exsolução.

Partição de $\mathrm{Cr}$, Fe e Mg entre as fases exsolvidas $\mathrm{A}$ partição do $\mathrm{Cr}$ entre a fase aluminosa e ferrífera é semelhante, havendo pequena preferência do $\mathrm{Cr}$ pela fase aluminosa em composições mais cromíferas. Na Figura 2 esta preferência pode ser observada pela inclinação das tie Unes entre as duas fases exsolvidas. Esta partição levemente preferencial é observada em algumas ocorrências naturais (e.g. Loferski \& Lipin 1983, Cândia 1983) mas não é constante em todos os casos.

As composições das fases exsolvidas, plotadas em diagrama $\mathrm{Fe}^{+2} /\left(\mathrm{Fe}^{+2}+\mathrm{Mg}\right) \times \mathrm{Cr} /(\mathrm{Cr}+\mathrm{Al})$, mostram que o $\mathrm{Mg}$ particiona preferencialmente para a fase aluminosa, enquanto o $\mathrm{Fe}^{+2}$ particiona para a fase ferrífera (Ver o exemplo de Mangabal I e II na Figura 4). Como a partição do Cr entre as duas fases exsolvidas é praticamante igual, a razão $\mathrm{Cr} /(\mathrm{Cr}+$ $\mathrm{Al})$ reflete essencialmente a variação do Al. O resultado da partição preferencial do $\mathrm{Mg}$ e do $\mathrm{Fe}^{+2}$ resulta em fases exsolvidas constituídas principalmente pêlos termos espinélio $\left(\mathrm{MgAl}_{2} \mathrm{O}_{4}\right)$ e magnetita $\left(\mathrm{Fe}_{3} \mathrm{O}_{4}\right)$.

Evolução do processo de exsolução A exsolução entre espinélios é um processo observado também em escala sub-microscópica. Moore \& Crawford (1978) identifi- 

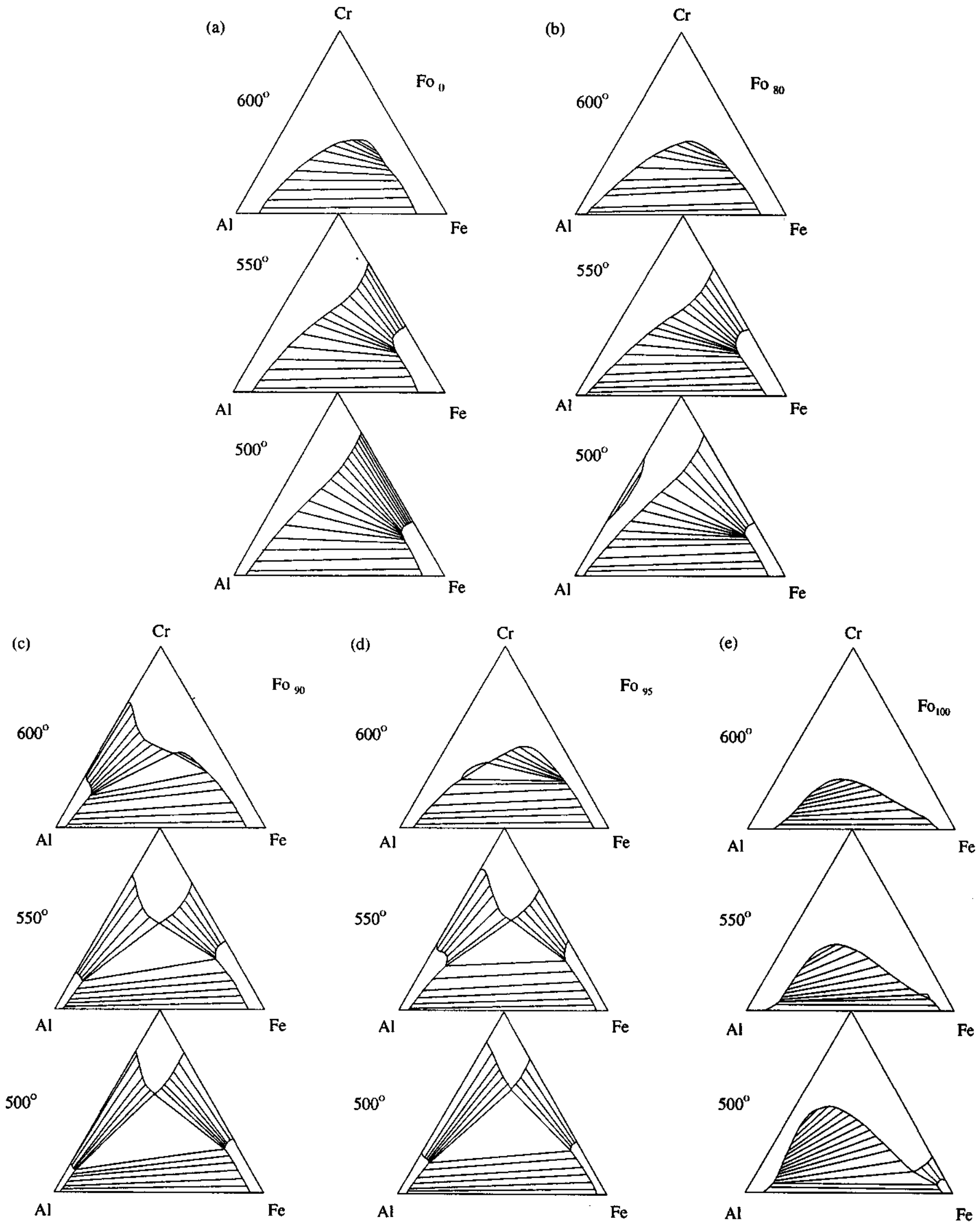

Figura 2 - Lacunas de miscibilidade em cromo-espinélios determinadas por Sack \& Ghiorso (199Ib) Figure 2 - Miscibility gap in chrome-spinels as determined by Sack \& Ghiorso (1 991 b). 


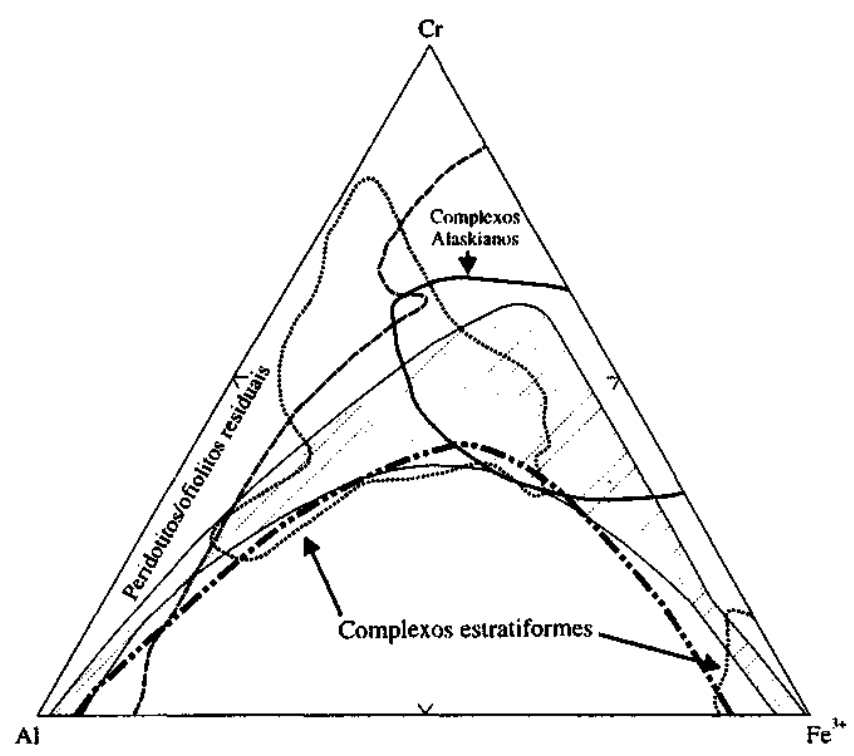

Figura 3 - Campos composicionais de cromo-espinélios de complexos estratiformes, alaskianos e alpinos segundo Jan \& Windley (1990). Os campos levam em conta o conteúdo de Ti, o qual é somado pêlos autores ao $\mathrm{Fe}^{+3}$.A região hachurada contem as curvas solvus determinadas a partir das exsoluções de espinélios naturais (Purvis et al. 1972, Muir \& Naldrett 1973, Springer 1974, Steele et al. 1977, Nilson 1981, Loferski \& Lipin 1983, Jan et al. 1992, Cândia \& Gaspar 1996). A curva desenhada corresponde ao solvus de Sack \& Ghiorso (1991 b) para Foso e $600^{\circ} \mathrm{C}$ (Figura 2).

Figure 3 - Compositional ranges of chrome-spinels from stratiform, alaskian, and alpine type complexes according to Jan \& Windley (1990). The compositional ranges include Ti which is added to $\mathrm{Fe}^{+3}$. Hachured field contain the solvus curves determined from natural spinel exsolutions (Purvis et al. 1972, Muir \& Naldrett 1973, Springer 1974, Steele et al 1977, Nilson 1981, Loferski \& Lipin 1983, Jan et al 1992, Cândia \& Gaspar 1996). Drawn curve corresponds to the solvus from Sack \& Ghiorso (1991 b) for Foso and $600^{\circ} \mathrm{C}$ (Figure 2)

caram decomposição espinoidal em espinélios naturais de Rodoya, Noruega, na forma de intercrescimentos entre lamelas de aproximadamente $100 \mathrm{~A}^{\circ}$ de largura, de fase aluminosa e ferrífera que, nesta escala, têm seu grau de simetria diminuído, podendo ser ortorrômbico ou tetragonal. Já em escala microscópica, Loferski \& Lipin (1983) descrevem texturas complexas que demonstram mais de um episódio de desmistura: porções ferríferas exsol vidas dentro de hospedeiro aluminoso apresentam finas lamelas de composição aluminosa. Esse episódio subsequente está também presente no hospedeiro aluminoso na forma de estreitas lamelas ferríferas. Espinélios em estágiqs mais avançados de desmistura mostram essas duas fases distribuídas em porções maiores (e.g. Jan et al. 1992, Nilson 1981), as quais tendem, com a continuação do processo, a formar grãos compostos, formados somente por duas porções contínuas, onde cada porção representa uma fase (e.g. Muir \& Naldrett 1973, Cândia \& Gaspar 1996). .O processo termina com a separação física das duas fases em cristais individualizados (e.g. Springer 1974).

Exsoluções de ilmenita Além das desmisturas acima referidas, exsoluções de ilmenita em cromo-espinélio são também descritas por Purvis et al. (1972), Muir \& Naldrett

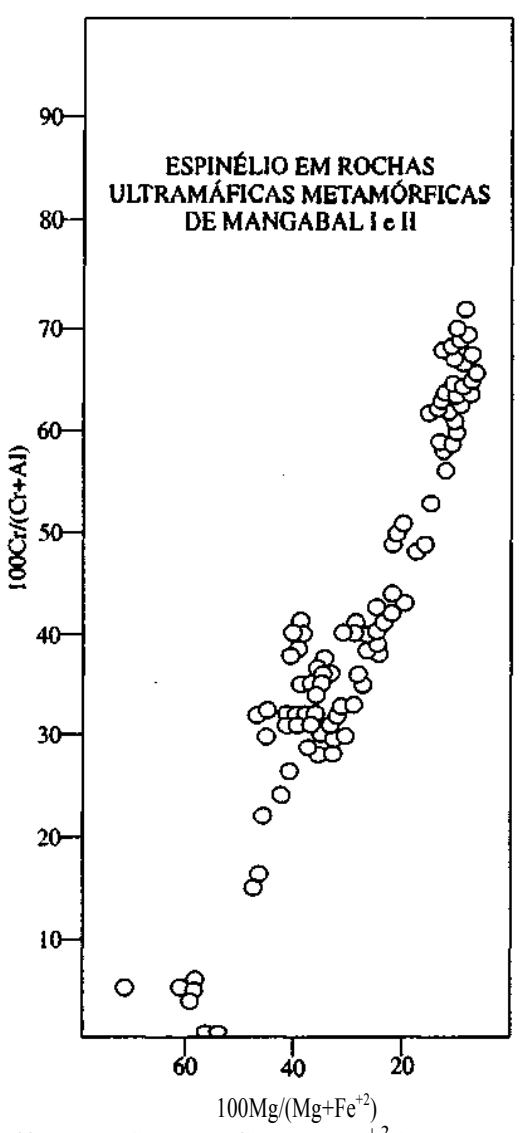

Figura $4-\mathrm{Cr} / \mathrm{f} \mathrm{Cr}+\mathrm{Al})$ vs $\mathrm{Mg} /\left(\mathrm{Mg}+\mathrm{Fe}^{+2}\right)$ para os espinélios exsolvidos de Mangabal I e II (Cândia \& Gaspar 1996).

Figure $4-\mathrm{Cr} /(\mathrm{Cr}+\mathrm{Al})$ vs $\mathrm{Mg} /\left(\mathrm{Mg}+\mathrm{Fe}^{+2}\right)$ for exsolved spinels from

Mangabal I and II (Cândia \& Gaspar 1995).

(1973), Boe (1978), Eales \& Snowden (1979), Putnis \& Price (1979) e Jan et al. (1992). As lamelas de ilmenita podem desenvolver-se por oxidação em espinélios de composição ferrífera, tanto em cromitas ferríferas quanto nas fases ferríferas de cromitas exsol vidas. Este fato demonstra que o Ti tem forte preferência pela fase magnetítica. Também neste caso a desmistura pode ocorrer sequenciadamente na forma de lamelas sub-microscópicas (Putnis \& Price 1979), microscópicas, grãos compostos e finalmente ocorrer a separação física das fases, formando grãos individualizados.

DISCUSSÃO A utilização da composição de cromo-espinélios para interpretações petrogenéticas deve se revestir de uma análise cuidadosa de todos os processsos a que os espinélios e a própria rocha foram submetidos. Em condições sub-solidus, as exsoluções acima descritas representam um fenómeno físico que necessita ser investigado a cada caso. É claro que uma vez instalado o processo de desmistura em escala microscópica, e caso não identificado, cada análise pontual por microssonda eletrônica passa a representar um somatório, em proporção desconhecida, das fases exsolvidas. Quando devidamente identificado, as análises poderão fornecer as composições dos termos exsolvidos. De qualquer forma, a recuperação da composição original do cromo-espinélio desmisturado é extremamente dificil.

Embora cromo-espinélios de composição intra-solvus possam persistir metaestavelmente (Henderson 1975), os dados da literatura mostram que o metamorfismo é um forte catalizador dos processos de desmistura dos cromo-espinélios. $\mathrm{O}$ campo composicional dos espinélios metamórficos citados 
por Evans e Frost (1975), representa, de modo geral, as composições possíveis dos espinélios no campo sub-solidus (metamórfico), concordando com o campo indicado nos diagramas de Sack e Ghiorso (1 991 b) (Figura 2). No detalhe, entretanto, a composição do espinélio deve ser investigada caso a caso.

No campo metamórfico, os espinélios podem participar de reações com fases silicáticas. Um cromo-espinélio exsolvido em fase aluminosa mais fase ferrífera, pode ter o seu componente aluminoso envolvido em reações com fases silicatadas, por exemplo, na formação de clinocloro. A formação desta clorita através da reação

Olivina $+\mathrm{Opx}+$ Espinélio aluminoso $+\mathrm{H}_{2} \mathrm{O}=$ Clinocloro

pode esgotar o fase aluminosa, deixando unicamente a fase ferrífera (magnetita cromífera) na associação. O campo de estabilidade do clinocloro em rochas ultramáficas se estende da fácies xisto-verde até o final da fácies anfibolito (Jenkins 1981). O clinocloro admite $\mathrm{Cr}$ em sua estrutura, podendo incorporar o $\mathrm{Cr}$ que estava contido no espinélio. Em condições metamórficas mais enérgicas o clinocloro se quebra dando origem a associações com espinélio aluminoso.

Em paragêneses com anfibólios e/ou piroxênios, o componente aluminoso dos espinélios participa dos reequilíbrios mineralógicos que envolvem componentes edeníticos e/ou tschermakíticos nos silicatos. Como todas essas reações podem modificar a composição dos espinélios é fundamental investigar detalhadamente a paragênese mineral à qual o espinélio está vinculado.

CONCLUSÕES Exsoluções em cromo-espinélios naturais, descritas por vários autores, podem ser interpretadas através dos modelos desenvolvidos a partir de cálculos termodinâmicos (Sack \& Ghiorso, 1991a, b). O processo de desmistura pode ocorrer na forma de intercrescimentos: lamelares em escala sub-microcópica; lamelas, porções ou bastonetes em escala microscópica; e grãos compostos. A evolução pode levar à separação física das fases em grãos individualizados, quando então a exsolução deve ser interpretada.

O campo composicional dos espinélios de complexos estratiformes e alaskianos apresenta sobreposição parcial com lacunas de miscibilidade para cromo-espinélios, podendo sofrer exsoluções, enquanto o campo dos espinélios de rochas mantélicas tem sobreposição muito pequena com as lacunas de miscibilidade. A exsolução predominante em espinélios cromíferos ocorre entre os termos $\mathrm{Mg}(\mathrm{Al}, \mathrm{Cr})_{2} \mathrm{O}_{4}$ e $\mathrm{Fe}(\mathrm{Fe}, \mathrm{Cr})_{2} \mathrm{O}_{4}$. Ilmenita pode exsolver-se por oxidação de cromo-espinélios ferríferos, indicando que o Ti tem partição preferencial para a fase ferrífera.

No campo metamórfico, o termo $\mathrm{Mg}(\mathrm{Al}, \mathrm{Cr}){ }_{2} \mathrm{O}_{4}$ pode participar de reações com silicatos, como por exemplo na formação de clinocloro e nas reações tschermakíticas e/ou edeníticas em piroxênios e anfibólios. No campo do clinocloro, os reequilíbrios podem consumir totalmente a fase aluminosa, deixando unicamente a magnetita cromífera na associação metamórfica resultante. Acima do campo de estabilidade do clinocloro, reações metamórficas podem originar $\mathrm{MgAl}_{2} \mathrm{O}_{4}$.

A utilização da composição de espinélios cromíferos em interpretações petrogenéticas deve ser necessariamente precedida do estudo paragenético detalhado, particularmente no caso de rochas que sofreram reequilíbrios metamórficos. Intercrescimentos originados por exsolução devem ser cuidadosamente procurados antes de qualquer análise química pontual (por exemplo, o procedimento analítico padrão de analisar núcleo e borda, por microssonda eletrônica, pode levar a conclusões erróneas). Uma investigação cuidadosa e detalhada em imagens de elétrons retroespalhados é fortemente sugerida e deve preceder as análises por microssonda eletrônica. Os dados apresentados neste trabalho indicam que toda e qualquer interpretação baseada em cromo-espinélios deve ser muito cuidadosa. Interpretações magmáticas, no caso de corpos que tenham sido submetidos a um evento metamórfico importante, ficam ainda mais prejudicadas e podem não ser possíveis.

Agradecimentos Os autores agradecem o apoio financeiro do CNPq e da FAPESP e ao Dr. César Fonseca Ferreira Filho pela revisão que contribuiu para melhorar o manuscrito.

\section{REFERÊNCIAS}

BOE, P. 1978. Ilmenite exsolution intergrowths in chromite from Raisduoddar-Hal'di, Troms, Norway. Can. Mineral., 16:597-600.

CÂNDIA, M.A.F. 1983. Peírologia dos complexos Máficos-Ultrmáftcos de Mangabal l e Mangabal //, Sanclerlândia, Goiás. Tese de Doutorado, Universidade de São Paulo, 400p.

CÂNDIA, M.A.F. \& GASPAR, J.C. 1996. Chromian spinels in metamorphosed ultramafic rocks from Mangabal I and II complexas, Goiás, Brazil. Mineral.Petrol., no prelo.

DICK, H.J.B. \& BULLEN, T. 1984. Chromian spinel as a petrogenetic indicator in abyssal and Alpine-type peridotites and spatially associated lavas. Contr.Mineral.Petrol., 86:54-76.

EALES, H.V. \& SNOWDEN, D.V. 1979. Chromiferous spinels of the Elephanfs Head dike. Mineral. Dep., 14:227-242.

EVANS, B.W. \& FROST, B.R. 1975. Chrome-spinel in progressive metamorphism - A preliminary analysis. Geochim.Cosmochim. Acta, 39:959-972.

HAGGERTY, S.E. 1991. Oxide mineralogy of the upper mantle. In D.H. Lindsley Ed., Oxide Minerais: Petrologic and Magnetic significance. Reviews in Minealogy, Mineral. Soe. Amei:, 25:355-416.

HAGGERTY, S.E. 1994. Upper mantle mineralogy. Invited Lectures. International Symposium on the Physics and Chemistry of The Upper Mantle. São Paulo, Brazil, 33 - 82.

HENDERSON, P. 1975. Reaction trends shown by chrome-spinels of the Rhum layered intrusion. Geochim.Cosmochim. Acta, 39:1035-1044.
IRVINE, T.N. 1967. Chromian spinel as a petrogentic indicator. Part 2. Petrologic applications. Can.Jour. Earth Sei., 4:71-103.

JAN, M.Q., KHAN, M.A.\& WINDLEY, B.F. 1992. Exsolution in Al-Cr-Fe -rich spinels from the Chilas mafic-ultramafic complex, Pakistan. Amer. Mineral., 77:1074-1079.

JAN, M. Q. \& WINDLEY, B.F. 1990. Chromian spinel-silicate chemistry in ultramafic rocks of the Jijal complex, Northwest Pakistan. Jour. Pefro/., 31(3): 667-715.

JENKINS, D.M. 1981. Experimental phase relations of hydrous peridotites modelled in the system hhO - $\mathrm{CaO}-\mathrm{MgO}-\mathrm{AhOs}-\mathrm{SiO}$. Contr. Mineral. Petrol., 77, 166-176.

LOFERSKI, P.J. \& LIPIN, B. R. 1983. Exsolution in metamorphosed chromite from the Red Lodge district, Montana. Amer. Mineral., 68:777-789.

MOORE, A.C. \& CRAWFORD, D. 1978. Spinodal decomposition in naturaly occurring non-cubic spinels. Nature, 274:237-239.

MUIR, J.E. \& NALDRETT, A.J. 1973. A natural occurrence of two-phase chromiun-bearing spinels. Can. Mineral., 11:930-939.

NILSON, A. A. 1981. The nature of the Americano do Brasil mafic-ultramafic complex and associated sulfide mineralization, Goiás, Brazil. Tese de Doutorado, Universidade de Western Ontario, London, Canadá. 460p.

PURVIS, A.C.; NESBITT, R.W.\& HALLBERG, J.A. 1972. The geology of part of the Carr Boyd rocks complex and its associated nickel mineralization, Western Austrália. Econ. GeoL, 67:1093-1113. 
PUTNIS, A. \& PRICE, G.D. 1979. The nature and significance of exsolved phases in some chromian spinels from the Rhum Layered intrusion. Mineral. Mag., 43:519-526.

SACK, R. O. \& GHIORSO, M.S. 1991a. An internally consistent model for the thermodynamic properties of $\mathrm{Fe}-\mathrm{Mg}$-titanomagnetite-aluminate spinels. Contr. Mineral. Petrol, 106:479-505.

SACK, R. O. \& GHIORSO, M.S. 1991 b. Chromian spinels as petrogenetic indicators: thermodynamics and petrological aplications. Amei: Minerai, 76:827-847.

SPRINGER, R.K. 1974. Contact metamorr^iosed ultramafic rocks in the Western Sierra Nevada Foothills, Califórnia. Jour. Petrol., 15 (0:160-195.
STEELE, I.; BISHOP, F.C.; SMITH, J.V.\& WINDLEY, B.F. 1977. The Fiskenaesset complex, West Greenland. Part III: Chemistry of silicate and oxide minerais from oxide-bearing rocks, mostly from Qeqertarssuatsiaq. Bulletin Gronlands Geologiske Undersogelse, 124, $38 \mathrm{p}$.

STOWE, C.W. 1994. Compositions and tectonic settings of chromite deposits through time. Econ. Geol., 89:528-546.

MANUSCRITO A899

Recebido em 02 de dezembro de 1996

Revisão do autor em 25 de janeiro de 1997 Revisã o aceita em 29 de janeiro de 1997 